Robert Lewis

\title{
Bioenergetics In Search Of A Secure Self
}

International Institute for

Bioenergetic

Analysis

Bioenergetic Analysis

17. Volume, No. 1, 2007, Page 135-164

Psychosozial-Verlag

DOI: 10.30820/0743-4804-2007-17-135

\section{熈 Psychosozial-Verlag}


Bibliographic information of Die Deutsche Nationalbibliothek (The German Library) The Deutsche Nationalbibliothek lists this publication in the Deutsche Nationalbibliografie; detailed bibliographic data are available at http://dnb.d-nb.de.

2007 Psychosozial-Verlag GmbH \& Co. KG, Gießen, Germany info@psychosozial-verlag.de www.psychosozial-verlag.de

\section{(C) $(\mathcal{D Q} \Theta$}

This work is licensed under the Creative Commons Attribution-NonCommercialNoDerivatives 4.0 International License (CC BY-NC-ND 4.0). This license allows private use and unmodified distribution, but prohibits editing and commercial use (further information can be found at: https://creativecommons.org/licenses/by-nc-nd/4.0/). The terms of the Creative Commons licence only apply to the original material. The reuse of material from other sources (marked with a reference) such as charts, illustrations, photos and text extracts may require further permission for use from the respective copyrights holder.

Cover image: Theo van Doesburg: Heroische Bewegung (Heroic Movement), 1916 Draft design: Atelier Warminski, Büdingen

https://doi.org/10.30820/0743-4804-2007-17

ISBN (PDF-E-Book) 978-3-8379-6887-3

ISBN (Print) 978-3-89806-704-1

ISSN (Online) 2747-8882 · ISSN (Print) 0743-4804 


\section{Bioenergetics in Search of a Secure Self}

Robert Lewis

\section{Summary}

This paper, based on my personal experience and more recently available biographical and autobiographical sources, is an attempt to reevaluate classical (Lowenian) bioenergetic analysis from a perspective based on recent research from the attachment paradigm. Specifically, it explores the use of the body, its energy and sexuality as substitutes for a secure relationship with a caregiver.

Key words: attachment, secure base, avoidant, shock, dissociated, psychosomatic unity.

(In this paper I will use the masculine pronoun for purposes of stylistic simplicity.)

\section{Introduction}

This paper ${ }^{1}$ is an important clarification for me and I hope for others. In it I am relying heavily on my own experience of Al Lowen over the 48 years that I have known him. For years as a young man I idealized Lowen and felt soothed and secure that he had the answers to life's

1 I would like to thank Marlee Manning and David Campbell for first calling my attention to attachment research and literature. I also thank Margit Koemeda, Peter Fernald and David Finlay for their substantial editorial assisstence. 
problems. Unfortunately for all of us, I would argue, he called the therapy he created "Bioenergetic Analysis « rather than Lowenian therapy. Furthermore, like many therapists, as he became aware of problems in himself, he saw them in his patients. He also saw them as givens in the human condition, at least in our western, contemporary culture. As was and still is his style, he expressed his beliefs with great conviction.

Because of my personal history with him, it has been important to me over the years that I gain a more objective perspective on his life and work. Lowen's candor in his Festschrift interview in the IIBA Journal (1990) and his autobiography (2004) helped me to understand with more clarity the relationship of his mind and body. This, in turn, enabled me both to preserve the bioenergetic treasures he gave us and to better see how easy it had been as a bioenergetic patient to surrender my psyche-soma in the hope of being cured. This is an intensely personal paper, perhaps a later day version of a paper (1996) entitled: Bioenergetic Analysis: My voyage to self-discovery. But the paper is also at the same time a commentary on a topic with which the IIBA (International Institute for Bioenergetic Analysis) is currently struggling as it attempts to chart a realistic course with Lowen no longer at it's helm. The topic I am referring to is the proper scope and importance of the therapist-patient relationship in the theory and practice of Bioenergetic Analysis.

\section{A. Underlying Assumptions: In this Regard, the CENTRAL THESIS OF MY PAPER IS BUILT ON A NUMBER OF UNDERLYING ASSUMPTIONS.}

1. Therapists pick the modality that suits their own proclivities ... specifically, their own capacity for intimacy/autonomy, their own attachment style.

2. There is always a relational significance to any therapy process; it may be explicitly and fully acknowledged or not.

3. In the latter case, regardless of the explicitly stated vehicle of healing, the relational process will operate, out of awareness, on an implicit, nonverbal level. 


\section{B. My Central Thesis is that}

4. in bioenergetic analysis (better described as Reichian/Lowenian therapy), the above relational significance has been distorted in a manner that weakens the otherwise deep healing power of a relational somato-psychic approach.

5. This distortion, which Lowen inherited from Reich, is at the heart of a poignant attempt to find a personal solution to Lowen's deep woundedness. Further, this distortion:

a) is richly documented in recent autobiographical material from Lowen himself;

b) must be understood and faced if we are to integrate our powerful psychosomatic legacy with a more mutual and realistic model of the clinical encounter.

While the above propositions can probably be illustrated from a number of relationally-oriented perspectives such a self-psychology, object-relations theory, etc., I have found the attachment paradigm (with its empirically derived model of normative development) particularly helpful in illuminating how relationship issues are woven into the fabric of bioenergetic analysis.

It is clear that Lowen has left us a rich legacy in the clarity and depth of his understanding of the body and its dynamic interaction with our thoughts, feelings and emotions. He and Reich are indeed the giants on whose shoulders we who follow stand. Lowen's passion and penetrating insights about the life of the body are clearly unmatched. But we are also left with the practical question as to how therapy actually works. I am suggesting that to properly evaluate any school of therapy, the interactive field is so complex, that, for a start, we are well advised to understand the relationship between who the founder is as a person and the »method «, the therapeutic edifice he is presenting as »the way«. Finally, I am aware that many of my colleagues no longer practice »classical « or Lowenian bioenergetics. They are no longer poor copies (as I was for the first five or more years of my practice) of Dr. Lowen himself. Nonetheless, it behooves us to look carefully at where we come from, and, to date, I am not 
aware that the message in this paper has found its way easily into print.

\section{History and Background}

My Early Training and Therapy:

Bioenergetics and the three charter members of the institute in New York City were my second family. I bonded deeply and early in my career with Alexander Lowen, John Pierrakos and William Walling who were each at one time or another my therapists and mentors. For years, their truths were my dogma. Slowly this changed, as I had to face how little I had actually been able in my bioenergetic therapies to deal with the pre-symbolic, nonverbal issues that had drawn me in the first place to a body-oriented approach. Actually, all along the way I had the occasional experience in which reality disturbed my dogmatic use of bioenergetics.

One occurred during a workshop in New York in which Bill, John and $\mathrm{Al}$ each worked in a different area of a large loft space. Participants would move around the room and be worked with by each of my three idealized attachment figures. It was both frightening and deeply relieving to discover that Bill, John and Al each focused and worked on completely different issues with the same person. The message landed: Either there was not a story that could be read in the form and motility of each workshop participant's body, or that story was so complex (currently, I would add, and so influenced, momentby-moment, out of awareness, by the unique limbic conversation with each therapist), that each of my three mentors trusted themselves to work with that part of the story that spoke to them at the moment. Slowly, I became able to maintain my respect and affection for colleagues, experienced pediatricians for instance, who found some of the Reichian/Lowenian propositions about parents and children simplistic. I could value them as people and even consider that bioenergetics might not have all the answers. 


\section{Winnicott and my Abiding Professional Interest in Early Terrors for which there are no Words:}

Then there were my »unthinkable anxieties«. I felt deeply spoken to by the work of Balint, Guntrip and especially Winnicott. Indeed while I was still in bioenergetic therapy I formed a transference to Winnicott; I found myself wishing that my own body-oriented therapy had been more informed by Winnicott's deep understanding of pre-symbolic issues. In particular, the essay in which he described the » mind as the locus of the False Self « (Winnicott, 1949), galvanized my sense that the head was a misunderstood part of the body in bioenergetics. Over several decades, I elaborated the somatic aspects of this alternative, Winnicottian view of the dissociated mind and body. I called it scephalic shock ‘. I consider it my most important contribution to our work, and it plays a central part in the main thrust of this paper.

\section{The Attachment Paradigm and its Implications for Relationship:}

The attachment paradigm is a work in progress, generating further empirical research that in turn enriches its models and lends them more detail and sophistication. Mary Ainsworth and colleagues (1978) did the first empirical, observational studies that focused on the normative (healthy) developmental psychology of attachment. A multitude of confirming studies have brought an exciting new empirical and predictive power to our field. Not surprisingly their model stresses the importance of sensitive and responsive parenting as the heart of what results in a secure, vital child. I would imagine that the entire bioenergetic community is as excited as I am by empirically rigorous findings that we can intuitively embrace, that make psychosomatic sense to us, and that confirm the truth of what Ferenczi, Balint, Spitz, Winnicott, Stern and others have already given us.

But there is a problem here. In the attachment model the relatively secure mother possesses an essential quality that enables her to be 
sensitive and responsive to her child. This is the capacity to see, consider and relate to her child as an autonomous being with rhythms, feelings, intentions and perspectives of its own. Her secure infant senses his (for simplicity's sake I will use the masculine pronoun) efficacy in the many exchanges every day, from the earliest moments, as he both regulates and is regulated by the mutual interaction with his mother. Further, he experiences her recognizing his movement as a gesture, his babbling as the beginning of speech. Thus, to their surprise, Ainsworth and her colleagues (1978) discovered that the factor that distinguished the mothers whose infants were rated as secure at one year from those rated as insecure was not the quantity of physical contact that their children received, but the quality of contact. Quality referred to attunement, the ability to tune into the child's unique rhythms that was, for instance, reflected in the space given or not given for the child himself to initiate the contact.

The bioenergetic problem that we are left with here, I would suggest, is that the Reichian/Lowenian developmental model tends to be so exclusively quantitative that it simply does not map onto the qualitative factors supported by controlled, longitudinal research. The classical bioeneretic model is about the amount of time (three years) that the baby should be nursed and given body contact. I will return to this theme, but for now, let me say that it would be reassuring to believe that Lowenian bioenergetic theory takes for granted the above crucial parental capacity to tune in and consider the child's unique rhythms, intentions and desires. But this is not the case. The Lowenian bioenergetic infant's self consists of a desire/need to be nursed and held for three years. The parental qualities that predict a child who will be nursed and held in such a way that it becomes a secure individual are simply not in focus and therefore not dealt with in Lowenian bioenergetic theory and practice. These same qualities were sorely lacking in the parents of both Reich and Lowen. Thus Lowen is not able to describe what he never experienced. What he can tell us about is the attributes his parents did have. For instance, his mother's obsessive and shaming preoccupation with his bodily functions, his father's easy-going, un-ambitious nature.

Attachment research (Fonagy et al., 2002) has now followed in- 
secure infants whose insecure parents did a poor job of reading their intentions and desires into early adulthood and found that they are lacking in this same ability to reflect on the inner life of others. Attachment-oriented clinicians such as Holmes (1993) and LyonsRuth et al. (2004) tell us that the way a secure parent is with his child is a good model for an effective therapist. A basic tenet of the bioenergetic model is that one can read a person's secrets, conflicts and traumas in the form and motility of his body. While most of us value this insight deeply, I would suggest that this tenet also curiously reproduces the way an insecure parent inadequately appreciates and therefore diminishes the autonomy and ultimately unknowable inner life of its insecure child.

On a practical level, over the years, many colleagues have come to and then left bioenergetics, often citing its lack of relationship between therapist and patient as an integral, embodied part of the therapeutic process. In Lowen's written corpus the emphasis is strongly on the therapist as a guide, and on the transformative process as between the patient and his body. Many therapists who have stayed involved in bioenergetics were able to do so by not directly questioning Lowenian bioenergetics, but rather by finding their own way to be present to the two-person relationship going on in the room. Others (Clauer, 1995; Finlay, 1999; Heinrich, 1999; Hilton, 2000) have argued strongly for a more relational focus in our work.

\section{Main Thesis}

\section{Proposed}

Over my many years in the bioenergetic community I have contributed articles that attempted to integrate a developmental, relational perspective into our psychosomatic approach. But it was only last month at the IIBA conference in Massachusetts, thirty-six years after my first article, that I was able to get to the heart of my lingering dissatisfaction with the official Lowenian model of bioenergetic analysis. I was helped to do this by looking at some recently available 
biographical material about Dr. Lowen from an attachment perspective.

What became clear to me was that both Alexander Lowen, and his teacher, Wilhelm Reich, came from families of origin in which they had two strikes against them. Both were insecurely attached and sexually overstimulated children. If you want to check this, I refer you to Sharaf's biography of Reich (1983), Lowen's recent autobiography, and an interview of Lowen on his $80^{\text {th }}$ birthday (1990).

I believe that these two gifted men, each in their own way, created a school of therapy which reflected their doomed attempt to compensate for the inner emptiness that in turn resulted from their lack of ever having had a fundamentally secure relationship with their fundamentally insecure parents. Their solution was to substitute their bodies, their sexuality and energy for the missing external secure base. This is not to minimize the deep and abiding gift they gave to our field and society with their pioneering focus on the body and its vitality. It is rather to illuminate the subtle lack of focus in classical bioenergetic analysis on the qualities that enable a person to parent a child whose sexuality is a natural part of a secure self. Indeed, the wounded healers of any persuasion, body-oriented or not, are an unlikely source for the requisite parental qualities of basic security in oneself and a natural sensitivity to the people in one's life. Thus, the debt we owe to the prospective, normative research of Ainsworth and others in the attachment tradition.

\section{Impressionistically Rendered, by Putting the above Proposition in a First-Person Narrative of Al Lowen's Experience:}

$»$ I never became attached securely to my parents ... they weren't present enough, attuned enough, affirming enough ... so I became attached to my body, its athleticism, its sexual feelings ... but it left a void; the endorphins only go so far ... with no core sense of security and belonging, I became inflamed by my prematurely awakened sexuality; I was driven by my sexual feelings; I sexualized things that were not sexual in their 
nature ... (sexuality became the solution to problems that were not sexual). Never having bonded securely as an infant, true intimacy was difficult for me. Not having the comfort in and with myself of a child that was attuned to, as an adult I could only make contact with someone, see them as a person, if they needed me, that is, if they came to me as a patient. Sadly, that also meant that I could not surrender myself to a therapist who might help me, by how they were with me, to repair my narcissistic wounds. So I tried to use my brilliant mind to heal via understanding. But being a psychosomatic unity, one cannot be sexually driven without being also mentally driven. So, while both Reich and I have made deep and abiding contributions to our field and the larger society, we are also accurately described as brilliant but wounded healers who could not tolerate opposition to our ideas. Our minds and ideas were both our salvation and our torment.«

Even brilliant ideas can become maddening when they are an attempted solution to an insane anguish: If you doubt this, contemplate two such gifted men as Reich and Lowen spending their lifetimes trying to get us out of our heads and into our bodies, in a vicarious search for a peace of mind which they never found. Some of you know that I have called this cephalic shock. In the biographical and autobiographical material that I will be citing, Lowen frequently mentions the threat of insanity, which is often warded off by masturbation, athletics, sexuality and working with the body. $\mathrm{He}$ is, in my opinion, describing cephalic shock, or as Winnicott understood it, psychotic, unthinkable anxiety. Lowen calls it the mind/body split, Winnicott (1962) also called it »falling forever, having no relationship to the body« (p. 58).

So, to reiterate the central issue which I will attempt to illustrate in the remainder of this essay, bioenergetic analysis can be understood as a life-long attempt to find in the body a better substitute than the dissociated mind for the missing, attuned, maternal (parental) care. We are describing here an attempt to restore psycho-somatic unity by escaping the dissociated mind (mind as the locus of the false self) and getting back to the body. This attachment to the body is then a more wholesome, but still inadequate replacement for the original failed secure base with one's parents. 


\section{Consequences}

There are a number of consequences that I believe follow from the above proposition.

1. The underlying fear of insanity in both Reich and Lowen is responsible for the paradoxical failure of bioenergetic analysis to include the head (which is experienced as housing the dissociated mind) along with the rest of the body as part of a truly psycho-somatic unity.

2. The belief system, which I will call Reichian/Lowenian bioenergetics, that results from this inherently flawed attempt to restore psychosomatic unity, is, by definition, a rigid system of thought. On the one hand, the product of two brilliant minds, it is a truly profound contribution to the understanding of psyche and soma in health and in illness. But, inevitably, on the other hand, it is the product of two dissociated minds, and as a substitute for the missing security that comes only from a secure relational base, cannot be questioned.

3. As already stated, the Lowenian bioenergetic vision suffers from a subtle, at times not so subtle, lack of understanding of the personal qualities in a parent that recent research has shown to predict a secure child. The subtlety is to be found in the way Reichian principles are imposed as explanations that oversimplify life issues.

4. There is an alternative model (there are many) of the function of the therapeutic relationship than that which Lowen has given us that I will attempt to illustrate; first, by describing my own bioenergetic therapy experience, and then by exploring our differing views on grounding and shock.

\section{My Journey into Bioenergetic Therapy}

These are cautionary tales about what may well be going on psychosomatically in any therapy approach that deals explicitly with the body, but does not view the central task of therapy as engaging and reworking the patient's embodied attachment relationships. The tales are also a commentary on how the attachment style of each therapist 
and of his preferred therapeutic method impose a specific attachment dynamic on the patient.

Towards the end of my 10 years of therapy with the three men who founded the bioenergetic institute, I finally found the courage to be fully in the room, that is, there were two of us present. Most of the rest of the time my compliant, avoidant self was quite comfortable surrendering my body to the therapy with the understanding that once my underlying stasis and biopathy was corrected, I would somehow be returned a healthy psychosomatic self. In hindsight, I was only too happy to go along with this understanding of what bioenergetic therapy involved: I would not have to deal with relational intimacy of which I was terrified. In this story we look at the shifting attachment relationship which my avoidant style makes with my therapist's own attachment style and, additionally, at the attachment significance of the therapeutic method in question. Therapists choose and work in a modality that matches their gifts and personal comfort level with intimacy/autonomy.

In my first therapy the talking and the body work did not threaten to get too close to my hidden self and seemed a small enough price to pay in exchange for a relationship which, crucially, kept me from feeling alone. One time Bill, my therapist grabbed me and we wrestled, and I actually felt that some of the frozen shock in me let go. But I continued to dread the silences that threatened whenever there was a pause in the activity of our bodywork and talking. Bill died seven years into my therapy with him. In the midst of my grieving for him, I felt what seemed like too much shock of an abandoned infant that cannot survive and conserves what energy it has by freezing down close to the core. I sensed that it was this abandoned infant in me that had been so terrified of the inchoate abyss of silence, and I developed an abiding professional interest in early terrors for which there are no words.

In my second therapy, this time with Alexander Lowen, I was still watching the interaction from a secret, broken place within myself, but I was a little less avoidant. Less terrified of my grief and brokenness, I was less content with a bioenergetic method that never asked me about my internal experience. The use of my body and its energy as a 
self-object to stand-in for an attuned, responsive relationship with another human being was not working as well for me as it allegedly had for Dr. Lowen. As I lay back over the Bioenergetic stool, I barely heard a whisper from my secret self, wishing that I could just lie there in my oral collapse and not do anything ... just luxuriate in my apnea ... slow down and face the part of me that was mostly dead in my chest, and maybe even come to life a bit as a result. But I am not sure that I really made sense of the whisper until some time after the therapy ended, and so I »breathed « on top of this half dead, low energy, despicable part of me, convinced that $\mathrm{Al}$ had no patience for such lack of energy.

In the grounding position, the dynamic shifted slightly, but as I had done for most of my career as a patient, from the unattached place where I lived, I never stopped watching the interaction between my therapist and my body. From the waist down, my body had a higher charge and energy than my upper body with which I was more identified. So, for some minutes, as I stayed in the grounding position, Al Lowen sat, seemingly fascinated, perhaps, I thought, even enraptured with the energy and vibrations that emanated from my legs and pelvis. The mostly dead child in my chest, who has never been enough, felt deeply envious of my strong lower body which did not have to do anything more than to release its tension and energy to hold the attention of my therapist.

My final bioenergetic therapy was with John Pierrakos. About a dozen years earlier, I had an important experience with John as a member of a group of bioenergetic therapists that he was leading. Actually, generally speaking, in my contacts with John as a senior colleague, I was very drawn to the warmth and considerateness I felt from him. While John was focused on the identified patient in the center of the group circle, I somewhat avoidantly sat down next to him ... wanting the contact, thinking that he wouldn't notice me absorbing his warmth. So I was a bit startled when I felt his hand on mine, but I was really stunned when I turned towards John to show my appreciation and I realized that he was focused intently on the »patient « in the center of the circle. Indeed, he seemed barely aware that he had touched me. John's implicit gesture went beneath my 
avoidant, False Self and found me in a way that no touch done as a body technique could have. I knew and felt in that moment something about secure attachment that was new. John had touched me not just with his hand, but with his humanity. I am reminded of Conger's (1994) words:

$» \ldots$ only genuine presence and true contact brings forth the deep healing of our injured humanity...there is no technique, no clever use of words, and no substitute for the intuitive nature stepping forth as human soul« (p. 90).

This was definitely a »now moment « as described by the Process of Change Study Group (Stern et al., 1998). In that moment there was a shift in my »implicit relational knowing " (Lyons-Ruth, 1998) about how I could be with someone and thus my attachment status shifted, even if fleetingly, towards secure. In that moment John was with me in a way that a secure parent is with her soon to be secure infant many times a day, and for a while my isolated psyche was not watching from someplace in my head; I was just there, in the room. As opposed to the moment with Lowen when I felt excluded from his attachment to my lower body, this time, on a level below self-consciousness, John's hand sent and my hand received a message that my bodily self need do nothing other than be alive. Although the »thank you «I was about to give him was genuine, it was from a false self place that did not know love freely given.

Fast forward to twelve years later, and I am in an individual therapy session with John. He is pounding on my chest chakra, and suddenly my entire career as a patient flashes before me. When, as Woody Allen might have urged, I asked myself, my heart pounding much louder than John was pounding, am I finally going to show up? As some of you may know, John was particularly interested in energy, charkas, and auras. But, determined this time not to lose myself in his therapeutic belief system, while he was still pounding on my chest, I said, »I don't know if you are interested in what's going on for me ... but while you are working on my chakra ... I am thinking, , what a stupid shit you are and that I would like to tear your head off your shoulders!!« 
John stopped and seemed genuinely interested in what I had said, even though it had interrupted his work. Nothing succeeds like success, so I then told John what had been happening spontaneously in my body recently in my daily life outside the office i.e., I had a new sense of unity when I held my head up in a way that released the tension at the base of my skull. This was truly attachment individuation at work. I was in the room with John, putting my subjective reality on a par with and even ahead of what I perceived as his belief system. I then asked John to confirm my body reality by reading my aura while I held my head in this position. He liked the blue hues he saw. I cannot convey the intensity of joy and aliveness, the inner light of integrity that came over me as I left that session, and which stayed with me for several weeks. I must have sensed from my earlier encounter with his implicit warmth that John would stay present and receive the first direct expression of protest and hate I had ever made to a therapist. In doing this John made me feel that he valued me more than the chakras, energies and procedures to which he had seemed so attached, and which I would no longer accept as a substitute for a contactful, secure relationship. In conclusion, a therapist who, by his sensitivity and responsiveness to your body and soul, fosters a secure attachment with and in you, is a blessing.

\section{The Nature of Healthy (Secure) Relationships in Life and in Therapy: A Bioenergetic Model amiss}

The following quotes are from an interview that Lowen gave in 1990 (Lowen, 1990). Here Lowen speaks about Reich, and, as I read it, many therapists, himself included:

Well, »naturalness is a funny word for Reich, because while he says »natural «, I don't know if he ever knew what naturalness is. How can he, given that background? Being that tormented, that obsessed with sex, how can he know what naturalness is? All he knows is that he has a 
tremendous sexual drive« (p. 4). Now remember, Lowen is not just talking about Reich; I submit that he is talking about the world that he knows best, that includes himself and the patients and therapists that have been a big part of his world. If you doubt this, listen to his response to a question as to how secure in her sexuality Reich's mother was: »No, of course not. If she were secure in her sexuality, Reich might not have been a psychoanalyst!«

A minute earlier in the interview $\mathrm{Al}$ is asked what he makes of the fact that Reich had such early sexual relations with his nurses:

»I think that saved his life and his sanity. You can see that this boy (and man) was sexually tormented all his life. And that is not normal. That is compulsive. He is obsessed with sex. But that doesn't mean that he is screwy! We are all obsessed with sex in this culture. I know I am. Once in a while you meet somebody who isn't obsessed with sex, and you realize what a difference there is between the way you feel and the way a really healthy person feels about sex ... and the reason he (Reich) was obsessed with sex is because it came upon him at an age when he couldn't deal with it. How can you deal with it when you are over-excited as a child with a mother who is beautiful, seductive, voluptuous and soft?«

I have no problem with this as far as it goes. Why should I? I am probably as obsessed with sex as most of my colleagues, and I credit my mother's seductiveness with me for a good measure of it. But what is out of focus, what is missing in Lowenian bioenergetics, is a description of the qualities that enable a person to parent a child whose sexuality is a natural part of a secure self. My wife for instance, is not obsessed with sex. But what was it about her parents that gave her a secure base, a sense that she belonged, a basic comfort with herself and a natural sensitivity to the people around her? It must have been something balanced and secure in their own beings that would never have allowed sexuality to become so seductive, so acted out, so crazy-making. They were like the relatively secure parents who tend to raise children who test (in double-blind rating) as secure. These people, who van Ijzendoorn \& Bakermans-Kranenburg (1996) and other attachment researchers consistently find, make up about $60 \%$ of 
not-at-risk populations, are sensitive and responsive to their children, give them firm boundaries, and accept their protest without retaliation. In this regard, Tuccillo (2006) has recently proposed a much-needed somato-psychic, relational model for the healthy development of human sexuality. If the reader is a therapist, this description may strike him as a touch unreal, because such people do not spend much, if any, time in therapy and therapists, who work a lot and spend a lot of time with colleagues, may not meet such people very often. I say this because of a personal conviction that most therapists (wounded healers) were not securely attached children, even though their own therapies may have helped them rewire their limbic imbalances in a more secure direction. I do not know if anyone has done research on the attachment status of therapists, but I wonder how many of us recognize ourselves in this description (Lewis et al., 2001) of 3, 4 and 5 year olds:

»Happy, socially competent, resilient, persistent, likeable, and empathic with others. Had more friends, was relaxed about intimacy, solved problems on his own when he could, and sought help when he needed it«. This is typically the way teachers describe children who showed secure attachment behaviors at 15 months (p. 74).

Turning to the rendering of Lowen's family background in his autobiography (Lowen, 2004), I find once again that something crucial is missing. As in Reich's story, the conflicting parental personalities are described. We are told that as a child Lowen was severely shamed around sexuality, and that he did not have a warm emotional life at home. Considering the obsession with sexuality, the narcissistic lack of contact with people in everyday life and the lifelong struggle to accept failure that he shares with us in his interview, it rings hollow that turning to his body via masturbation and sports could actually substitute for the lack of a fundamentally secure relationship with his fundamentally insecure parents. Lowen (2004) tells us that,

»every infant or child needs an unconditional commitment from its parent ... Whenever a parent fails a child in this regard ... each such ex- 
perience undermines the child's feeling of being secure in its world ... once childhood ends, one cannot be fulfilled by another person. We must then stand on our own feet ... But it is not hopeless, because we have our two legs to stand on, even though they feel insecure. As an adult, one can take appropriate measures to strengthen one's legs and to make them feel more secure, and one may need some help in that endeavor« (pp. 155-156).

I find that if this is to mean more than any physical trainer does to strengthen your leg musculature and your balance, then it is about an attuned caregiver/therapist helping you to tolerate the deep feelings of despair, rage, terror, etc. that open up as you get in touch with your body and open up its feelings. I believe that something paradoxical occurs to the extent that patients experience a significant deepening in their sense of grounding in their work with Lowen. They bond with him deeply via sharing his conscious belief that he is just a guide and that the essential process is taking place exclusively in their bodies.

I believe that one experiences the missing security and one's body slowly changes in the way that Lowen describes in his chapters on grounding, but as part of a process in which one becomes deeply attached to the person who is doing the shepherding. The specifics of what kind of nonverbal interventions ... attunement, acceptance, being seen, quality of contact, etc. ... are optimally effective in changing the psyche-soma of each patient vary with the specific relational history that is embodied in the form and motility of their body. This also depends naturally on the body and soul of the therapist; on what kind of shepherd he/she is ... how attuned, how sensitive, how accepting of protest. The details vary as to how, in his daily life, each patient learns to live closer to the life and feeling in his body. What I have not seen in my forty-five years in the bioenergetic community is a successful outcome when the attempt is made to substitute an attachment to one's own body for the original missing secure relationship. »It is relationships with people that break our spirits and our connection with our bodies. It is relationships with people that heal them « (Hilton, 1988/89).

Lowen's (2004) vision is quite different: »Bioenergetic therapy does not offer treatment for emotional problems. Therapy is a self-healing 
process in which the therapist is a guide and facilitator «(p. 221). I find this quite divorced from a grounded description of two real people in a room together, one of whom is witnessing and being entrusted with the other's unbearable anguish. Lowen's stance here follows from my main thesis: He employs his mind and his sexuality to defend against deep emotional woundedness, insecurity. Thus he cannot really be in the room with his patient's terror and agony and thus retreats up into his head as a guide who depends on his understanding of $»$ the human condition ...«(p. 221).

\section{Groundng and Cephalic Shock}

A third source that has helped me to formulate this essay is Helfaer's review (2005) of Lowen's autobiography. Helfaer says, »From this voice (Al's) I gained insight into my own life journey and a deeper understanding of Bioenergetics « (p. 135). While I might have written the same sentence, Phil and I come to very different conclusions about Lowen's recent (1990 and 2004) autobiographical revelations.

Actually, it was back in 1976 that I first put in print my divergent understanding of the relation of the head to the rest of the body (Lewis, 1976). Over the years, I developed my clinical construct, cephalic shock (1984, 1986, 1998), more fully. Lowen (2004), as he tells his story, sensed, following his therapy with Reich, that his basic insecurity was still with him. He also realized that Reich himself had not dealt with his own deep humiliation and resultant messianic grandiosity. So, going his own way, Lowen pursued a more secure connection and contact with the earth through his pelvis, legs and feet. This, then, became the unique focus on grounding of Bioenergetic Analysis. In his autobiography Lowen makes it clear that he has struggled mightily to personally achieve this secure connection to the earth right into the ninth decade of his life.

I, on the other hand, following my first Bioenergetic therapy with William Walling, realized that I did not experience my shocked head as part of my body and could not trust it to another human being. So, although Lowen and I both sought a more grounded body, mine in- 
cluded the head. He tried to let down into a connection of his legs and feet into the ground; I tried to deal directly with the shock in my head that had been causing me to unnaturally fight the force of gravity since I was an infant. Neither of us had had much peace of mind. Until his autobiography, Lowen has not written directly about his being in a state of shock. Without using the word, however, he has previously shared the story of the spontaneous screams that came out of him during his initial therapy session with Reich. As he describes it in the recent book (2004):

»... but I felt something in my personality that was not healthy. The screams had surprised me, because I did not feel any fear. My conscious mind, which was split off from the action, was an observer, unconnected to what was happening« (p. 39).

I would argue that this is a very clear description of a state of shock in which a trauma has split a dissociated mind from its anchorage in a feeling body. Lowen tells us on the same page that it was his mother's eyes which caused him to freeze and that »I knew that I had to do a lot more work in therapy to free myself from that fear « (pp. 39-40). I believe that the older he got, the more Al Lowen realized that the grounding, as he originally understood it, did not do the job unless it also included his shocked-since-infancy-head. I would ask the reader to view the touching photo of Lowen as an infant in the autobiography (2004), about which he says, »even as a baby my head is straining from my body« (p. 95).

In 1995, when Lowen was 84, he tells us that he suffered a breakdown in his knees secondary to the way he unconsciously held his head forward (got ahead of himself) in reaction to his basic Oedipal insecurity. His knee cartilage took the brunt of this un-centered, imbalanced stance. »Even though I tried to keep myself straight, I could never find the position of my feet that would give me the good sense of security that many other people have" (Lowen 2004, p. 198). Lowen explains, »This problem is not solved from the head but from the ground up. We must start with the feet « (p. 138). He continues: 
»I had come to some awareness that the neurotic character structure was a frozen state, as if the person had been shocked at some earlier point in his life (p. 142) ... I had been in a state of shock that prevented me from seeing the deeper dynamics of my problems. The issue was still grounding, but I needed a technique that would help me break through the shock state $\ll$ (p. 143).

The older he gets, the more Lowen puts in writing the basic insecurity and shock in his structure and his life long, poignant struggle to free himself from the driven sanity of a man who cannot risk losing his head. Each innovation is presented as finally creating the energetic connection he is seeking. He has the patient raise his head while kicking the bed; he has the patient do somersaults; he hits the patient on the head. Al explains, »At age 87, I began to feel the tensions in my neck muscles, and I realized that it was associated with my fear of losing my head or breaking my neck. This fear of losing the head or breaking the neck is common to all of my patients « (pp. 164-165). At 93 years of age, Lowen is still on the quest with a new exercise, which he calls »connecting the feet to the earth «, the goal of which is to » have the vibrations begin with the feet and move up the body « (p. 240). In summary, Lowen's odyssey is about never having come to terms sufficiently with the shock in his head (cephalic shock) to find the peace of mind that eluded him. I do not know if I have done any better with my own shock, but I believe I had no choice but to look it more directly in the face/head.

Finally, in a number of earlier papers I have made the following point (Lewis, 1986), which, I believe, bears repeating. Sometimes our words reveal what we truly believe. In all of Lowen's books and on $p$. 145 of Helfaer's essay (2005), the head is designated as something other than a part of the body: "After that, he (Al Lowen) was equally excited about re-discovering the somersault, age 93, as a way to work with the cervical block, allowing a better connection between bead and body and, thus, fuller grounding" (p. 145). I would ask the reader to ponder the absurdity, the anatomical impossibility, one might even say the insanity, of it being common practice, in a discipline dedicated to psychosomatic unity, to understand and thus refer to the head not as part of the body, but as something additional. 


\section{Belief Systems Help us to Cope with Personal Tragedies that are too Painful and Shameful to Grieve}

In this regard, Reich and Lowen, like all of us, needed a set of beliefs to help them with the intuitive sense of how small and frail and unknowing they really were in the larger scheme of things. In fact, in the event that the reader has been discouraged rather than encouraged by the drift of my essay, I hope that my written work over the past thirty-two years demonstrates my continued passionate commitment to our evolving model of bioenergetic analysis, which strives to stay true to the life of the body, even as it is enriched by attachment, relational and neurobiological perspectives. But this paper is about missing pieces in a puzzle that I believe most of us can use in our journey as therapists. We all become attached to our patients, to their pain, to their vitality. We become attached to our beliefs, to our techniques, whatever adds to our security and makes us feel more alive. We are therefore always well advised to check that there are two of us in the therapy office, each with an inner life.

So, even if, too often, I take for granted how much life and health I was given by my Reichian/Lowenian therapies, please bear witness that I also feel grateful. It is somehow easy for me to forget that my bioenergetic therapists were a second family to me, that they brought me to a place where hope outweighed despair. Paradoxically, in spite of the limitations of the classical bioenergetic model that I have been addressing, the therapy it spawned was fundamental to the rich, fullbodied personal and professional life that I have enjoyed. But the paradox is more apparent than real, because, praise the Lord, the bealing bumanity of my three bioenergetic therapists pulsed through, both in spite of and with the help of the model that made them feel most whole. Additionally, Lowen's clarity, for instance, about the physiology of panic (1967), and many other somato-psychic dynamics were gems that focused my embodied sense of the timbre and tension and flow and gesture of the other person in the consulting room. But this is NOT the topic of this essay. In truth, it is partly my lingering dis- 
appointment that I was not more relationally healed by my therapies that fuels the searching look I take in this essay at the inherent limitations of the bioenergetic model which prevailed in those years.

In this final section, I am going to explore a bit further what I have already called the rigidity of a model that attempts to substitute for the missing secure relational base. From this perspective, the model can be seen as a rigid system of thought, a belief system in support of which limited or no data are offered, and which cannot be questioned. I find that another attribute of this model, which I will explore in regard to sibling relationships, is its unreality. I will just touch lightly on a number of areas in which I see the model's rigidity and unreality come to bear. I refer those readers who are interested in more detail to my website (www.bodymindcentral.com) where a slightly longer version of this paper will be available within a year of this publication.

One basic area in which I believe this rigidity and unreality plays out is the issue of childrearing. In this regard, there are two qualities in a parent that I would highlight as signs of his being a secure person. The first is his acceptance of his inner intuitive sense of how to raise a child, and the second is his awareness of his relative helplessness and limited understanding regarding the complex mystery of the young life that has been entrusted to him. Lacking this inner security, Lowen tells us repeatedly in the autobiography (2004) and the Festschrift interview (1990), of the two linked belief systems that informed his work and brought a measure of sanity and meaning to his life.

The first is an amalgam that I will call socioanthropology, for lack of a better word. It enables Lowen to project his personal guilt and shame out into the culture at large and make them into everyone's problem. While there is truth in his formulation, there is also a denial of the particular shock and trauma through which he lived in his family of origin. Here, for instance, Lowen (2004) discusses the dynamics of the Oedipal situation:

»... most people in the Western world have both success and power. The collapse of their world is the impoverishment of their inner or emotional lives. Having committed themselves to success and power, they have little else to live for. And like Oedipus, they have become wanderers 
on the earth, uprooted beings who can find no peace anywhere. Each individual feels alienated, to some degree, from his fellowman, and each carries within him a deep sense of guilt that he does not understand. This is the existential condition of modern man« (pp. 121-122).

The second is a set of principles, most of which he inherited from Reich, which impose order on and offer oversimplified explanations for the messy business of raising a child. A central belief, for example, that appears throughout his writings is that a child will be healthy if it is nursed on demand and in contact with the warm body of the mother for the first three years of life. This belief system also specifies the grim results of any break in this continuous contact. Lowen (2004) explains:

»When a baby is born its ground is the warm and loving body of its mother. In most cultures before the turn of the century, the baby was connected to the mother's body by being carried on the mother's back for about three years (p. 153) .... This allowed the mother to nurse the baby any time it needed to be fed (p. 154) ... Every infant or child needs an unconditional commitment from its parent to be there for the child every time that the child needs that assurance or connection. Whenever a parent fails a child in this regard ... each such experience undermines that child's feeling of being secure in its world. That lack of security will be carried throughout life ...« (p. 155).

Lowen's words have great intuitive appeal. But is any data, any research offered in support of them? Lowen does not tend to offer empirical data in support of his assertions. He often gives descriptions of childrearing and other practices in cultures distant in time and place from our own Western industrial/technologically advanced societies. Since they are not referenced, they must be taken on faith.

On the other hand, off the written record, Lowen spoke with much more common sense. He knew that one can not actually raise a child according to a consciously held belief system. He and Leslie, his wife, only tried it once. Although he has remained committed to the Reichian principles in his written work, the life lessons of raising his son Fred were not lost on him. He told me personally on several occa- 
sions during his son's teen-age years, that the only way to really raise a child was to »muddle through it «. This advice helped me with our two adopted children. I must confess that after surviving the Watsonian behavioral principles which my own mother employed, and sensing the unreality of some of our own bioenergetic principles, I was actually somewhat relieved that my wife, Barbara and I, and our two adopted children would have to do the best we could without the prescribed three-year nursing experience. We would have to settle for less than perfection.

\section{Some Empirical Data}

After several decades of careful observational research led by Mary Ainsworth (1963, 1967, Ainsworth et al. 1978), the attachment paradigm provides us with an empirically based model of normal development. There is now a vast number of controlled, longitudinal, infant and mother-infant observational studies that have given us a new model of how a baby develops into a healthy child. While Ainsworth initially spent several years studying mothers and infants in Uganda, most of her definitive work was done in white, middle-class homes. It is difficult to relate recent empirical attachment research to Reichian/ Lowenian principles, belief-systems, and statements about the necessity of unconditional availability in raising a child. Even parents of infants, who prove to be secure children, are only in a matching, attuned state with them $30 \%$ of the time (Tronick, 1989). Parents who match the emotional state and rhythms of their infants in the midrange, rather than the extremes, have the best outcomes: They and their children are rated as secure. Similarly, it is the quality - the sensitivity and attunement to the physical contact - rather than the quantitative amount that codes for secure outcomes in the cutting-edge research (Ainsworth et al. 1971, 1978) of this era.

And finally, although they are acutely aware of bonding issues, attachment researchers find the strong correlation to be between a secure sense of self in the parents and security in their offspring. They have not come up with data to support the Reichian/Lowenian hy- 
pothesis that any quantitative break in the »unconditional « availability of the mother leads to life-long insecurity.

\section{No Man is an Island unto Himself, or where are my Siblings?}

This section details a legacy of unreality that I believe we inherit from an unexamined aspect of Al's narcissism: his relationship, or more accurately, his lack of relationship to his siblings. Again, because it bears repeating, I am exploring these issues in the hope that if we really face the ways in which Reich and Lowen, in the company of other heroic figures, had their Achilles' heels that weakened their roots, we will be both a humbler and more vital Institute. Our practice of bioenergetics will move towards an ever more sober and grounded somatic psychotherapy. In his recent essay (2005) Helfaer tells us how touched he was by the way Lowen spoke to him in a tender and protective way about his younger sister. I was as relieved to read this as I was shocked to learn five or ten years ago that $\mathrm{Al}$ actually had a younger sister named Sylvia. As in his conversation with me about »muddling through « childrearing, I believe we are dealing here with a profound split between the reality of what $\mathrm{Al}$ Lowen can in rare moments acknowledge in a private conversation, and the unrealities he enshrined in his self-healing vision of a bioenergetic model of health.

Over the years, $\mathrm{Al}$ told us old-timers time and again about his nuclear family-of-origin, himself, his father and mother. I listened carefully, and, as I say, was startled to discover that a sibling existed. The only place in all his writings that a sibling is mentioned is in his latest book (2004). Here, however he does not mention Sylvia, his living sister who was born when Al was four years old, but rather Sylvia's twin, the sister who died in her infancy. His comment is that her death did not affect him. Now, while Al was certainly not your average person, most of us come into this world either as only children or we learn early that we must share the joys and pains of life with our brothers and sisters. Al Lowen, however, seems on some level to accept what he tells us was his mother's image of him as her savior, 
whose success gave meaning to her otherwise empty life. Common sense, not to mention clinical experience, tells us how deeply a family is usually haunted, at least in our Western culture, by the death of a child. While Lowen may not have picked up a »messianic « (Lowen 2004, p. 92) strain in his personality until his encounter with Reich, he somehow created himself into such a special child that he was the only child.

The theory and practice of bioenergetic analysis has paid the heavy price of an impoverishment of both the rivalry and richness of an embodied sister-and-brotherhood. Children, no matter how brilliant, who cannot make peace with their brothers and sisters, are at risk for becoming thinkers who overvalue their own perspective. This seems more dangerous for an applied discipline that concerns itself with a model of psychosomatic health than, for instance, Kepler's predictions about planetary motion. Kepler's laws are easier to prove or disprove. Let me confess how immediate (non-theoretical) this issue is to me: Perhaps the purest murderous feelings I have ever felt were towards my own younger sister at the dinner table whenever she took the spotlight to say something, anything at all! But, finally, my concern with Lowen's siblings is about the main thesis of this paper: the blurred focus in Lowenian bioenergetics on his own crucial family dynamics and the consequently flawed model of the quality of relationships in a secure, bealthy family of parents and their children.

\section{And ... Speaking of the Truth}

About five years ago I wrote this definition of bioenergetic analysis:

»When you have no words for your feelings, for what happened to you, for what is missing in you, we listen to the inner resonance - of your inchoate secrets - as it lives in your body. We help you to sense and amplify this inner resonance until its movement comes close enough to the surface of your being to enter your consciousness.

But we also listen carefully to your words and we are touched by them when they come from a depth of your being that no one can put a hand on ...« 
I have italicized the sentence about spoken language, because words have long been second-class citizens in the pychosomatic equation of Reichian/Lowenian therapy. This has been the case because, in spite of the brilliant vision of psyche-soma equivalence, both men had a strong belief that words could not be trusted to convey a person's deeper truth. They, in common with most victims of family of origin trauma, had very personal reasons for this mistrust. Their primary attachment figures consciously disavowed and/or were unaware of their feelings, thoughts and behavior - such that their verbal descriptions of what took place denied Reich and Lowen's experience of that reality. This is commonly described as a particularly destructive aspect of trauma within the family. As is also well known, these patients, for many reasons, »live in their heads « and are both cut off from and do not trust their deeper feelings. But we also tend to filter our experience of others through our own structures: What if both Reich and Lowen, sensing their own cephalic shock (dissociation), assume that others' words are also not to be trusted as direct expressions of their essential being?

So, on the one hand, we bioenergetic therapists are lifesavers when we pay less attention to the words of the dissociated patients, and help them to come down into the life of their bodies. On the other hand, let those of us bioenergetic therapists, like Reich and Lowen, who have felt traumatically betrayed, be cautious that our deep mistrust of our own parents' words, does not blind us to the moments when our patients' words, come from a depth of their being that no one can put a hand on.

I hope that this essay has kindled an ongoing curiosity both as to how our attachment styles affect the mix of intimacy and autonomy we embody as therapists, and, how we are all at risk to attach everything from our own beliefs to our patients' vitality, in an attempt to heal our less than secure beginnings.

It may bear repeating that our creations are always more or less about ourselves. Most of us hope that they will speak to and touch others. In our field we offer personal help to others who have been significantly broken by life. I believe that the more genuine we can be, as wounded healers, about our own personal brokenness, the more 
healing our help will be. My work on cephalic shock is nothing if not about my struggle to live more fully in the moment. I hope I have been as candid about this as I ask of Reich and Lowen.

\section{Bibliography}

Ainsworth M (1963) The development of infant-mother interaction among the Ganda. In: Foss B (Ed) Determinants of Infant Behavior, Wiley, New York, 67-104.

Ainsworth M (1967) Infancy in Uganda: Infant Care and the Growth of Love, The Johns Hopkins University press, Baltimore.

Ainsworth M, Bell S, Blehar M, and Main M (1971, April) Physical Contact: A study of infant responsiveness and its relation to maternal handling «, Paper presented at the biennial meeting of the Society for Research in Child Development, Minneapolis, Minnesota.

Ainsworth M, Blehar M, Waters E, Wall S (1978) Patterns of Attachment: A Psychological Study of the Strange Situation. Erlbaum Associates, Hillsdale, H.J.

Clauer J (1995) Some Developmental Aspects of Body and Identity: Analytic-Imaginal Body Psychotherapy. Presented at the First congress of the European Federation of Bioenergetic Analysis/Psychotherapy, May, 1995 in Rome.

Conger J (1994) Character and Character Armor. The Body in Recovery, Frog, Ltd., Berkeley, California, 89-94.

Finlay D (1999) A Relational Approach to Bioenergetics. Bioenergetic Analysis. The Clinical Journal of the IIBA, 10 (2).

Fonagy P, Gergerly G, Jurist E, Target M (2002) Affect Regulation, Mentalization and the Development of the Self. Other Press, New York.

Heinrich V (1999) Physical phenomena of countertransference: therapist as a resonance body. Bioenergetic Analysis. The Clinical Journal of the IIBA, 10 (2) $19-31$.

Helfaer P (2005) Review of »Honoring the Body: The Autobiography of Alexander Lowen. Bioenergetic Analysis. The Clinical Journal of the IIBA, 15, 133-146.

Hilton R (1988/89) Narcissism and the therapist's resistance to working with the body. Bioenergetic Analysis. The Clinical Journal of the IIBA, 3 (2) 45-74.

Hilton R (2000) Bioenergetics and modes of therapeutic action. Presented at the International Conference on Bioenergetic Analysis, Montebello, Canada, May, 2000.

Holmes J (1993) John Bowlby and Attachment Theory. Routledge, London.

Lewis R (1976) Infancy and the head. Energy and Character 7 (3).Lewis R (1984) Cephalic shock as a somatic link to the false self personality. Comprehensive Psychotherapy, 4, Gordon and Breach, New York.

Lewis R (1986) Getting the head to really sit on one's shoulders: a first step in 
grounding the false self. Bioenergetic Analysis. The Clinical Journal of the IIBA, 2 (1) 56-77.

Lewis $R$ (1996) Bioenergetic analysis: My voyage to self-discovery. The Clinical Journal of the IIBA, 7 (1) 42-56.

Lewis R (1998) The trauma of cephalic shock: clinical case study. Bioenergetic Analysis. The Clinical Journal of the IIBA, 9 (1), 1-18.

Lewis T, Amini F, Lannon R (2001) A fiercer sea. A General Theory of Love, Vintage Books, New York, 66-99.

Lowen A (1967). The physiology of panic. The Betrayal of the Body. The Macmillan Company, New York, 161-182.

Lowen A (1990) An interview with Alexander Lowen. Bioenergetic Analysis. The Clinical Journal of the IIBA, 4 (1) 1-11.

Lowen A (2004) Honoring the Body. Bioenergetic Press, Alachua, Florida.

Lyons-Ruth K (1998) Implicit relational knowing: Its role in development and psychoanalytic treatment. Infant Mental Health Journal, 19, 282-291.

Lyons-Ruth K, Melnick S, Bronfman E, Sherry S, Llanas L (2004) Hostile-helpless relational models and disorganized attachment patterns between parents and their young children. In: Atkinson L \& Goldberg S (Eds) Attachment Issues in Psychopathology and Intervention. Lawrence Erlbaum, London.

Sharaf M (1983) Fury on Earth: A Biography of Wilhelm Reich. St. Martin's Press, New York.

Stern D, Sander L, Nahum J, Harrison A, Bruschweiler-Stern N, and Tronick E (1998) Non-interpretive mechanisms in psychoanalytic therapy. International Journal of Psycho-analysis, 79, 903-921.

Tronick E (1989) Emotions and emotional communication in infants. American Psychologist, 44, 112-119.

Tuccillo E (2006) A somatopsychic-relational model for growing an emotionally healthy, sexually open body from the ground up. Bioenergetic Analysis. The Clinical Journal of the IIBA, 16, 63-85.

Van Ijzendoorn M H \& Bakermans-Kranenburg M J (1996) Attachment representations in mothers, fathers, adolescents and clinical groups: A meta-analytic search for normative data. Journal of Consulting and Clinical Psychology, 64, $8-21$.

Winnicott D (1949) Mind and its relation to the psyche-soma. In: Through Pediatrics to Psychoanalysis (1975). Basic Books, New York, 243-254.

Winnicott D (1962) Ego integration in child development. In: The Maturational Processes and the Facilitating Environment (1965). International Universities Press, New York, 56-63. 


\section{About the Author}

Robert Lewis, M.D., in private practice in New York, is a senior trainer on the IIBA faculty, and a member of the clinical faculty of the NYU/Mount Sinai Medical Center. He has published extensively on the integration of early developmental and relational issues into the basic bioenergetic approach. R.Lewis has long been interested in the sensory-motor story which trauma engraves in our bodies. He coined the term »cephalic shock « to capture the psychosomatic experience of what Winnicott called the mind as the locus of the false self. His elucidation of Cephalic Shock and way of working with the head, voice, and diaphragmatic connections to the pelvis, are beyond words. $\mathrm{He}$ has found the attachment paradigm deeply confirming of the centrality of relationship in his clinical approach. R.Lewis aims for and is touched by the moments of encounter in which implicit mystery becomes almost palpable. He leads workshops in Europe and the Americas, and residential intensives on Long Island, New York.

Webpage: bodymindcentral.com

Robert Lewis, M.D., 155 East 91 st ST. \#1B, New York, NY 10128. E-mail:boblewis@inch.com 